\title{
PANORAMA DA DIMENSÃO POLÍTICA DA AGROECOLOGIA BRASILEIRA A PARTIR DO LEVANTAMENTO DE TESES E DISSERTAÇÕES NO CATÁLOGO DA CAPES
}

\author{
Frederico Castro de Carvalho \\ Rodrigo da Costa Caetanoii
}

\begin{abstract}
Resumo: no artigo apresenta-se a dimensão política da agroecologia, atrelada ao seu processo de consolidação como ciência no Brasil a partir do levantamento bibliográfico realizado no Catálogo de Teses e Dissertações da CAPES, realizado no segundo semestre de 2020, utilizando-se dos termos de busca: "agroecologia"AND"política", com aplicação do filtro temporal 2015 a 2019; foram encontrados 143 trabalhos em nível de pós-graduação stricto sensu. Os elementos utilizados para a seleção a partir da análise de conteúdo foram, principalmente, os títulos, os resumos e as palavras-chave, com o objetivo de observar e refletir acerca da interface agroecologia/política, que revelou apresentar elevado grau de complexidade, dialogando com diversas áreas do conhecimento. Assim, emergiram categorias que permitem compreender melhor a temática proposta e iniciar um debate profícuo, a saber: construção do conhecimento agroecológico e educação, políticas públicas, desenvolvimento, movimentos sociais e reforma agrária, redes, tecnologias sociais, gênero, saúde e outros.

Palavras-chave: conhecimento agroecológico 1; agricultura familiar 2; produção orgânica 3; políticas públicas 4; metodologia 5 .
\end{abstract}

\section{OVERVIEW OF THE POLITICAL DIMENSION OF BRAZILIAN AGROECOLOGY FROM THE SURVEY OF THESES AND DISSERTATIONS IN THE CAPES CATALOG}

\begin{abstract}
: the article presents the political dimension of agroecology, linked to the process of construction of agroecological knowledge in Brazil, based on a balance of academic publications. The bibliographic survey took place on the basis of the Capes Catalog of Theses and Dissertations, carried out in the second semester of 2020, using the search terms: "agroecology" AND "policy", with the application of the time filter 2015 to 2019; 143 studies were found at the stricto sensu graduate level. The elements used for the selection from the content analysis were, mainly, the titles, abstracts and keywords, with the aim
\end{abstract}

\footnotetext{
'Doutorando em Políticas Sociais na Universidade Estadual do Norte Fluminense Darcy Ribeiro e Professor do Instituto Federal do Espírito Santo, Campus Venda Nova do Imigrante. E-mail: frederico.castro@ifes.edu.br, https://orcid.org/0000-0002-6929-0216.

iiProfessor Associado da Universidade Estadual do Norte Fluminense Darcy Ribeiro e credenciado no Programa de Pós-Graduação em Políticas Sociais da mesma instituição. E-mail: profrodrigo@uenf.br, https://orcid.org/0000-0003-2509-4392.
} 
of observing and reflecting on the agroecology / policy interface, which revealed a high degree of complexity, dialoguing with different areas of knowledge. Thus, categories emerged that allow a better understanding of the proposed theme and initiate a fruitful debate, namely: education, public policies, development, social movements, networks, social technologies, gender and health.

Keywords: agroecological knowledge 1; family farming 2; organic production 3; public policies 4; methodology 5.

\section{RESUMEN DE LA DIMENSIÓN POLÍTICA DE LA AGROECOLOGÍA BRASILEÑA A PARTIR DE LA ENCUESTA DE TESIS Y DISERTACIONES EN EL CATÁLOGO DE CAPES}

Resumen: el artículo presenta la dimensión política de la agroecología, vinculada al proceso de construcción del conocimiento agroecológico en Brasil, a partir de un balance de publicaciones académicas. El relevamiento bibliográfico se realizó a partir del Catálogo de Tesis y Disertaciones de Capes, realizado en el segundo semestre de 2020, utilizando los términos de búsqueda: "agroecología" Y "política", con la aplicación del filtro de tiempo 2015 a 2019; Se encontraron 143 estudios a nivel de posgrado stricto sensu. Los elementos utilizados para la selección del análisis de contenido fueron, principalmente, los títulos, resúmenes y palabras clave, con el objetivo de observar y reflexionar sobre la interfaz agroecología / política, que reveló un alto grado de complejidad, dialogando con diferentes áreas del conocimiento. Así, surgieron categorías que permiten una mejor comprensión de la temática propuesta e inician un fructífero debate, a saber: educación, políticas públicas, desarrollo, movimientos sociales, redes, tecnologías sociales, género y salud.

Palabras clave: conocimiento agroecológico 1; agricultura familiar 2; producción orgánica 3; políticas públicas 4; metodología 5.

\section{Introdução}

A agroecologia ${ }^{1}$ é uma ciência que também se consolida por meio da sua dimensão política, aqui compreendida enquanto escala de ação e/ou proposição inerente às políticas públicas para respectiva área. Assim, as condições necessárias para disputar

\footnotetext{
${ }^{1}$ Segundo MOLINA (2011: 11) "con un enfoque teórico y metodológico que, utilizando varias disciplinas científicas, pretende estudiar la actividad agraria y agroalimentaria desde una perspectiva ecológica. Tu vocación es el análisis de todo tipo de proceso agrário en su sentido amplio[...]".
} 
agendas políticas foram desenvolvidas, cabendo ao Estado brasileiro assumir seu papel no apoio e no fortalecimento de um modelo de agricultura ambiental e socialmente sustentável (MOURA, 2016).

A inserção do enfoque agroecológico na agenda de políticas públicas setoriais no Brasil se propõe antagônica ao projeto de desenvolvimento rural preconizado desde os anos de 1960 pelo Estado brasileiro, sob a influência da modernização da agricultura baseada na "revolução verde". O seu público-alvo é o/a agricultor(a) familiar, tendo sua racionalidade e suas características culturais, ambientais, sociais e econômicas como os elementos estruturadores da práxis e da teoria agroecológica (PEREZ-CASSARINO, 2012).

Praticamente duas décadas após o início da mencionada modernização, bastante criticada pela desproporção entre os avanços tecnológicos e sociais, o debate do que viria a ser a agroecologia no país aconteceu, principalmente nos Encontros Brasileiros de Agricultura Alternativa (EBAAs), em 1981, 1984 e 1987. Nos EBAAs, destacou-se a participação de estudiosos de instituições de ensino, pesquisa e extensão rural, membros de ONGs, representantes de instituições públicas e privadas, lideranças de movimentos sociais, agricultores, bem como profissionais e estudantes das ciências agrárias, especialmente de agronomia. (LUZZI, 2007).

A diversidade de participantes nos eventos revela, em parte, a abordagem interdisciplinar da agroecologia, na busca de um entendimento científico integral dos fenômenos, a partir da coevolução sociedade-natureza. A construção de um "viés político" da agroecologia no Brasil tem com marco a Lei 7.794, de 20 de agosto de 2012, pois as legislações anteriores traziam como referencial à prática de agriculturas alternativas, ao modelo convencional, o conceito de agricultura orgânica².

\footnotetext{
${ }^{2}$ No contexto do surgimento de mecanismos nacionais de controle para a garantia da qualidade orgânica, em 1999, no Brasil, foi publicada a Instrução Normativa (IN) n 007/1999 do Ministério da Agricultura, Pecuária e Abastecimento (Mapa). Essa IN foi uma regulamentação acerca das normas e os procedimentos à produção orgânica no Brasil.
} 
O presente artigo é de natureza bibliográfica, caracterizado pela busca de produções científicas publicadas em determinado período, com o objetivo geral de observar e refletir acerca da atualidade da interface da agroecologia com a respectiva dimensão política à luz de outro paradigma que permita iniciar ou ensaiar um necessário debate epistemológico.

Na pesquisa apresenta-se o resultado do levantamento bibliográfico de trabalhos de pós-graduação stricto sensu na base Catálogo de Teses e Dissertações da Capes (https://catalogodeteses.capes.gov.br/catalogo-teses/) que abordam a dimensão política do campo do conhecimento agroecológico no Brasil, usando como recorte temporal os anos de 2015 a 2019, tendo em vista recentes contribuições sobre a temática.

Como o levantamento foi realizado durante os meses de agosto, setembro e outubro de 2020, não foi contemplado esse ano inconcluso, até mesmo porque existe um interstício entre a defesa e a publicação do trabalho no referido Catálogo. Utilizou-se os seguintes termos na busca textual: "agroecologia"AND"política". Com aplicação do "filtro" foram encontrados 143 trabalhos de pós-graduação stricto sensu (entre dissertações e teses). Para a organização do trabalho foi criada uma tabela Word contendo: nome do autor, título do trabalho, ano de defesa, programa, instituição, palavras-chave e categoria.

À melhor organização textual, estruturou-se duas seções. A primeira refere-se aos aspectos predominantemente quantitativos, destacando o levantamento e a distribuição da produção pelas regiões do Brasil. Em seguida, as categorias temáticas encontradas são analisadas à luz do cenário da agroecologia brasileira. Por fim, complementando o panorama, nas considerações finais enfatiza-se a dimensão política da agroecologia frente à emergência paradigmática que suscita o debate epistemológico. 


\section{Aspectos quantitativos preliminares: percentuais e diferenças regionais}

A partir da busca realizada com os referidos filtros, observa-se que dos 143 trabalhos encontrados $25 \%$ são do tipo teses (doutorado), 59,7\% dissertação de mestrado acadêmico e 15,3\% de mestrado profissional, considerando o total entre 2015 e 2019. Embora no Gráfico 1 (Publicações 2015-2019) os últimos anos revelarem uma queda do número de produções, não se pode confirmar uma tendência sem uma série ampliada. Por outro lado, nota-se a consolidação da agroecologia enquanto campo científico e avanço nas agendas de governos em níveis federal, estadual e municipal.

\section{Gráfico 1}

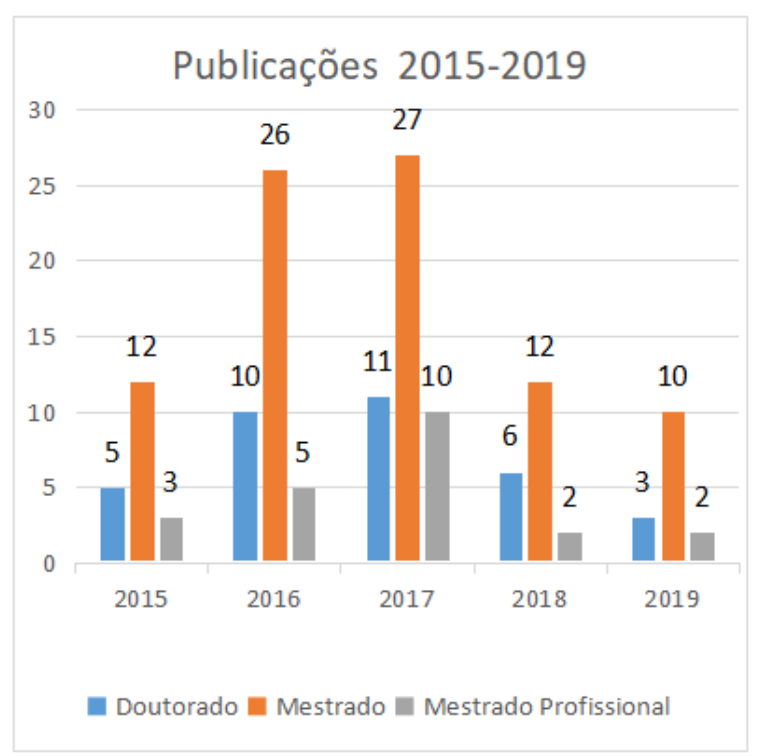

Fonte: Elaborado pela primeira autoria (2020).

O Gráfico 2, a seguir, assinala as áreas do conhecimento relacionadas aos materiais "filtrados", a saber: Multidisciplinar (54 trabalhos), Ciências humanas (50 trabalhos), Ciências sociais aplicadas (18 trabalhos), Ciências agrárias (17 trabalhos), Ciências da saúde (4 trabalhos), Linguística, letras e artes (1 trabalho). 


\section{Gráfico 2}

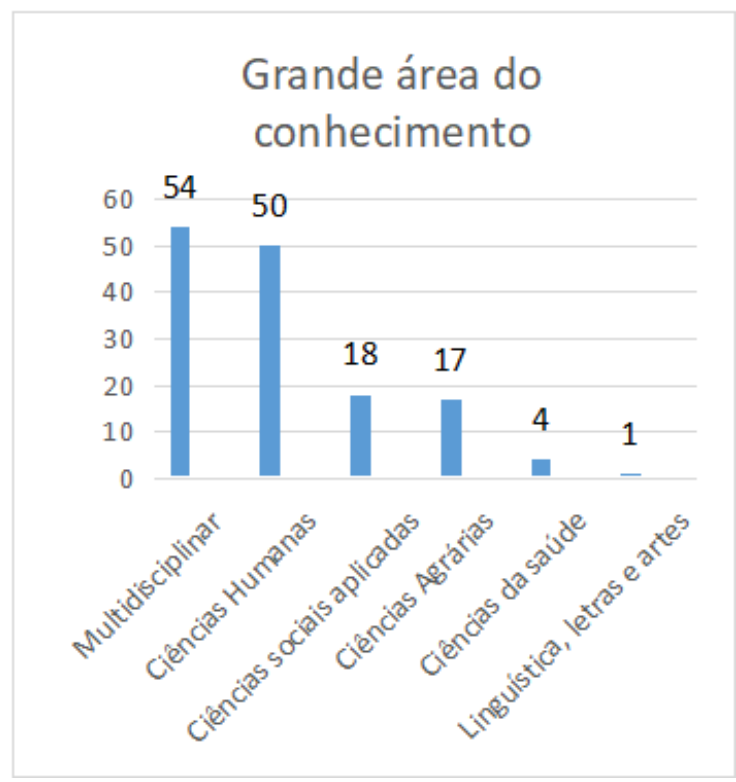

Fonte: Elaborado pela primeira autoria (2020).

A importância da questão alimentar como problemática social e suas inter-relações, cria convergências de produção de conhecimentos científicos em torno de modelos capazes de dar respostas sustentáveis à vida. A heterogeneidade de áreas coaduna o caráter interdisciplinar na dimensão política da agroecologia, segundo PORTO-GONÇALVES (2013: 209) "O que a espécie humana conseguiu por meio das agriculturas foi a segurança alimentar, expressão que hoje volta a ganhar o debate político".

Analisando a distribuição das publicações por macrorregiões do Instituto Brasileiro de Geografia e Estatística (IBGE), observa-se a concentração dos trabalhos no Sul - Sudeste brasileiro, totalizando 92 trabalhos dentre os 143. Na própria região Sudeste há discrepância, tendo em vista as 23 publicações no estado de São Paulo, 17 no Rio de Janeiro, 10 em Minas Gerais e 2 trabalhos no Espírito Santo.

Segundo SANTOS e SILVEIRA (2005: 105) "O meio técnico-científico-informacional não se impõe igualmente sobre o território". A herança da concentração industrial, gerida 
pelo Estado, fez convergir para o desenvolvimento no/do sudeste. Os maiores fluxos de capitais voltados à ciência e tecnologia também seguem essa tendência. Entrementes, quando se alcança 52 publicações contando com tantas instituições já consolidadas a valorização percentual pode ser relativizada.

\section{Gráfico 3}

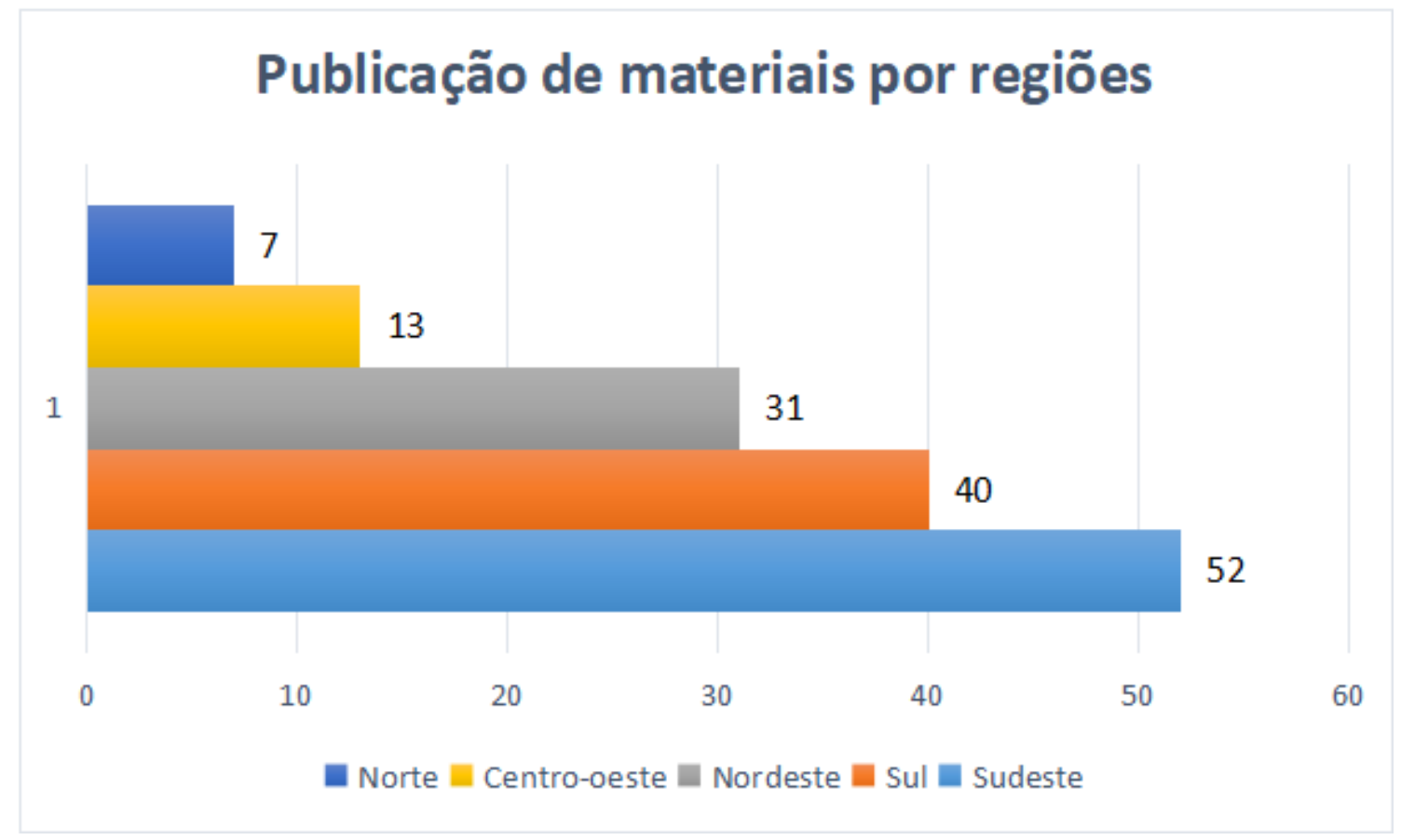

Fonte: Elaborado pela primeira autoria (2020).

Com 40 publicações, a região Sul foi pioneira na área desta pesquisa, com destaque para o estudo das redes agroecológicas no estado de Santa Catarina (SC), que contabiliza 18 trabalhos, enquanto que no Rio Grande do Sul são 12 e no Paraná 10 trabalhos. Na região Nordeste, com 31 publicações, a Paraíba conta com 8 trabalhos e Rio Grande Norte e Pernambuco com 6 trabalhos cada, contrastando com Alagoas e Piauí, que não apresentaram trabalhos agroecológicos a partir de um enfoque político entre 2015 e 2019, segundo os critérios da pesquisa. 
Na região Centro-Oeste 13 publicações foram filtradas, com destaque para o estudo das políticas públicas na Universidade de Brasília com 7 trabalhos. Na região Norte 7 publicações foram mapeadas, sendo 5 trabalhos no Pará, 1 no Amazonas e 1 em Roraima. Observando as unidades da federação, mais de $25 \%$ não publicaram trabalhos a partir de um enfoque político da agroecologia entre 2015 e 2019, conforme a pesquisa realizada no Catálogo da Capes.

Os dados estão no contexto da discrepante distribuição das instituições públicas de ensino superior pelo território nacional; enquanto no Sul-Sudeste, quase todo Nordeste e o Distrito Federal (DF) as produções indicaram a existência de grupos de estudos consolidados na temática, em quase todo Centro-Oeste e Norte os primeiros trabalhos surgiram após 2015, indicando um movimento de expansão da agroecologia.

O processo de interiorização das Instituições de Ensino Superior promovido entre 2002 e 2018, principalmente por meio do espraiamento da rede dos Institutos Federais (IF's), pode ter influenciado positivamente esse processo de expansão da Agroecologia a partir da renovação dos quadros de professores/pesquisadores com outros paradigmas e projetos.

\section{Categorias temáticas: uma noção do cenário da agroecologia brasileira}

Após estudo dos materiais emergiram, em maior proporcionalidade, 8 categorias temáticas, e uma nona categoria, outros, foi apresentada envolvendo temáticas atinentes à seara desta pesquisa; seu agrupamento ocorreu em virtude de uma menor recorrência nas publicações.

As categorias emergidas, apresentadas a seguir, são fruto da seleção considerando-se como critério a análise do conteúdo a partir dos títulos, palavras-chave e resumos. Com base na relevância dos conteúdos encontrados percebeu-se a necessidade de consultar 
16 trabalhos na íntegra, na busca das características básicas capazes de elucidar os elementos mais importantes das partes constitutivas da dimensão política da agroecologia brasileira.

\section{Gráfico 4}

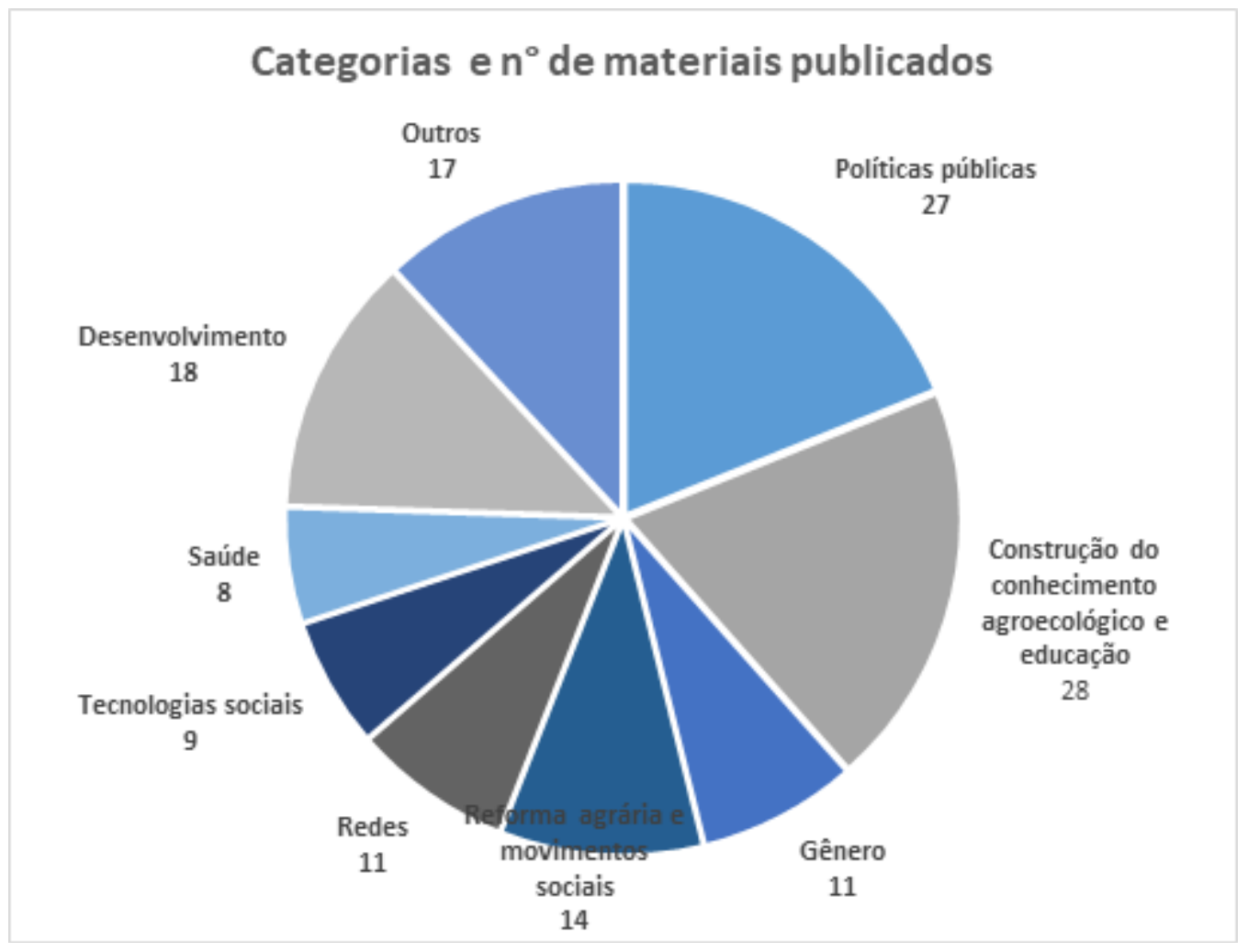

Fonte: Elaborado pela primeira autoria (2020).

As metodologias mais utilizadas nos trabalhos "filtrados" foram de caráter participativo, destacando-se as sistematizações de experiências e os estudos de caso. Dentre os diversos autores citados com regularidade nos trabalhos, destacam-se: Miguel Altieri, Paulo Freire, Stephen Gliessman, Eduardo Sevilla-Guzman, Boaventura de Souza-Santos, Francisco Caporal, José Antônio Costabeber, Eric Sabourin, Clara Nicholls, Lester Brown, Stéphane Guéneau, Cátia Grisa, Sérgio Schneider, Irene Cardoso, e Fritjof Capra. 
Construção do conhecimento agroecológico e educação: A agroecologia, enquanto ciência, possui uma breve história que se inicia no fim dos anos de $1980^{3}$. Destarte, o processo de construção dos conhecimentos agroecológicos é fundamental para a consolidação do saber agroecológico e do seu reconhecimento como campo científico.

Perto de $20 \%$ dos trabalhos que discutem a esfera política da agroecologia o fazem a partir de forte relação com os processos de construção do conhecimento agroecológico por meio da indissociabilidade: ensino, pesquisa e extensão. Segundo MENEZES (2017), a respeito dessa relação, está ocorrendo a formação e o desenvolvimento de um paradigma dentro do conhecimento científico do campo agrário. Foi possível notar que as discussões que envolvem políticas educacionais e modelos de ensino dialogam, geralmente, com o conceito de sustentabilidade, com as tradições e os saberes das comunidades em conjunto com o conhecimento acadêmico.

Destacam-se na produção da Construção do Conhecimento Agroecológico diálogos com os produtores do campo, das águas e das florestas através da Educação Popular (LOBO, 2019), Pedagogia da Alternância (VIEIRA, 2017); Educação Ambiental Crítica (ARAÚJO, 2019), Educação do campo (ZANELLI, 2015); Agroecopedagogia (MOSQUERA, 2018), dentre outras pedagogias holísticas, que surgem como alternativas de ensinoaprendizagem, reaproximam sociedade-natureza e melhor integram/contemplam os grupos sociais mais vulneráveis.

Diversos elementos comuns existem entre essas pedagogias, destacando-se a práxis, conversas estudante-natureza-comunidade, como instrumento de aprendizagem por meio de ação-reflexão-ação, configurando-se em atividade objetiva da ação transformadora, com base em tendências pedagógicas progressistas.

\footnotetext{
${ }^{3}$ Para o agrônomo chileno Miguel Altieri, um dos fundadores da ciência, a agroecologia "[...] é definida como a aplicação dos conceitos e princípios ecológicos para desenhar agroecossistemas sustentáveis [...] (2012: 104)".
} 
Políticas públicas: $19 \%$ das pesquisas, por aproximação, discutem a temática dimensão política da Agroecológica a partir de análises de políticas públicas desenvolvidas. O Programa Nacional de Fortalecimento da Agricultura Familiar (PRONAF), criado em 1995, foi recorrente nesta categoria, pois tanto trouxe a centralidade das políticas públicas para o ator social, agricultor(a) familiar, quanto surgiu como instrumento para construção de um novo modelo de desenvolvimento rural no país.

A Política Nacional de Agroecologia e Produção Orgânica (PNAPO), fruto de longo processo iniciado nos anos de 1970, envolveu diversos atores, tais como: movimentos sociais, movimentos de estudantes, professores, técnicos, Organizações Não Governamentais (ONG'S), associações, dentre outros. O Decreto do governo federal 7.794/2012 é uma espécie de culminância dentro do debate da dimensão política da agroecologia brasileira, tendo por objetivo integrar, articular e adequar políticas, programas e ações indutoras da transição agroecológica.

MOURA (2016) destaca as organizações das mulheres trabalhadoras rurais e camponesas, que em um contexto político favorável se articularam para a entrada da agroecologia na agenda governamental, como na formulação da PNAPO e do Plano Nacional de Agroecologia (PLANAPO). De maneira geral, os movimentos sociais do campo e o denominado movimento agroecológico foram fulcrais à construção de agendas favoráveis à agroecologia em níveis federal, estadual e municipal.

Para GRISA e SCHNEIDER (2014) a PNAPO foi criada em uma geração de políticas públicas para a agricultura familiar, na qual o referencial é a construção de mercados para segurança alimentar e sustentabilidade ambiental. Outras políticas como o Programa Nacional de Alimentação Escolar (PNAE), o Programa de Aquisição de Alimentos (PAA), a Política Nacional de Redução de Agrotóxicos (PNARA), o Programa Nacional de Educação na Reforma Agrária - PRONERA, a Política Nacional de Assistência Técnica e Extensão Rural para a Agricultura Familiar e Reforma Agrária - PNATER e o Programa Nacional de Assistência Técnica e Extensão Rural na Agricultura Familiar e na Reforma 
Agrária - PRONATER, apresentaram grande relevância nas discussões, uma vez que são voltadas ao público-alvo da agroecologia.

Desenvolvimento: Perto de $13 \%$ dos trabalhos trazem como foco modelos de desenvolvimento; diversas são as abordagens: sustentável, alternativa, rural, regional e territorial, coadunando com que LIMA (2016: 22) denominou "múltiplas faces do desenvolvimento". Pôde-se perceber que a agroecologia é articuladora de modelos de desenvolvimento alternativos ao modelo convencional. Nesse contexto, os conceitos de território e sustentabilidade são recorrentes nos debates, desvelando tanto assimetrias de relações de poder, quanto demanda por abordagem mais complexas nas propostas de organização do espaço.

Nos trabalhos "filtrados" desta categoria, os modelos apresentados dialogam em sua maioria com o conceito de desenvolvimento sustentável, que tem origem nas ações da Organização das Nações Unidas (ONU), na década de 1980.

A demanda por projetos de envolvimento sociedade-natureza conflita com as inseguranças da governabilidade brasileira. Em seus territórios, grupos de produtores (re)existem, como destaca RODRIGUES (2017) sobre o Espírito Santo, que diante do caráter emergente da dinâmica de desenvolvimento agroecológico e das incertezas sobre os seus desdobramentos, o território norte se destaca no sentido de abrigar práticas inovadoras associadas a um expressivo movimento camponês agroecológico.

De maneira geral, os materiais desta categoria caracterizam-se por compreender desenvolvimento além do crescimento econômico, mas como estratégia de vida; desenvolvimento como elemento da sustentabilidade sócio-ambiental na porção espacial envolvida.

Movimentos sociais e reforma agrária: Os movimentos sociais foram fundamentais para o desenvolvimento das lutas que culminaram na construção de uma série de políticas públicas voltadas à agricultura familiar e ao desenvolvimento rural sustentável, e in medias res a agroecologia, sobretudo o movimento agroecológico. Nesse contexto, 
a agroecologia é um movimento de transformação societária envolvendo um modelo de desenvolvimento rural no qual a terra é um bem da coletividade, sendo a reforma agrária fundamental dentro desta perspectiva.

Quase $10 \%$ dos trabalhos trazem os movimentos sociais rurais como foco do debate político agroecológico. Destaca-se nessa categoria o Movimento dos Trabalhadores Sem Terra - MST (SILVA, 2017; AGUIAR, 2016), que poderia constituir uma categoria à parte, superando a metade dos materiais desta categoria; o MST (re)produz as práticas agroecológicas como forma de resistência ao modelo agrícola convencional atrelado ao complexo agroindustrial. Também compõe a categoria a questão agrária (FACCO, 2019), a reforma agrária (IHA, 2017; ROSA, 2019), a resistência e luta pela terra (MARTINS, 2017; MERCADO, 2018), dentre outros assuntos que surgem em paralelo, bem como a Via Campesina e o Instituto de Agroecologia Latino Americano (IALA).

Compreende-se que a replicação das práticas agroecológicas, as estratégias de comércio e de redução da demanda por insumos externos à produção são fundamentais à associação da tipologia campesinato, que nessa categoria se "sobrepõe" ao conceito de agricultura familiar.

Gênero: Quase 8\% dos trabalhos destacam a importância de movimentos femininos (MOURA, 2018; ZARZAR, 2017) para o desenvolvimento da agroecologia no Brasil. A luta pelo pleno exercício da cidadania; a conquista de autonomia, participação e conquista de direitos, são relevantes nas discussões encontradas nos trabalhos "filtrados".

Milhares de agricultoras familiares e camponesas têm construído novos processos de gestão dos territórios como parte das mobilizações sociais para o desenvolvimento rural, realizadas por diversos movimentos e organizações presentes no campo da Agroecologia, assim como o feminismo e a Articulação do Semiárido Brasileiro (ASA), respectivamente. 
O grito da Marcha das Margaridas: "sem feminismo não há agroecologia", incluiu definitivamente a questão da mulher do campo enquanto sujeito político nas agendas das políticas públicas no Brasil. O movimento feminista teve, ao lado dos movimentos sociais rurais, uma participação fundamental para aprovação da PNAPO e seus planos assinados pela presidenta Dilma Rousseff (MOURA, 2018).

Redes: Quase 8\% dos trabalhos "filtrados" trazem as redes para o centro dos debates, e indicam que estas estruturas estão espalhadas pelo país, em todas as regiões, mas com estratégias e volumes diferenciados, conectando em seus territórios os diversos atores que as compõem e as tecem.

Na formação da Articulação Nacional de Agroecologia (ANA), em 2002, as relações e os processos sociais que a geraram, sua forma de ação em rede e sua expressão como parte do movimento agroecológico, impulsionaram o significado político da agroecologia, mobilizando atores, ações e propostas de uma nova utopia (BENSADON, 2016).

Outras redes, tais como Articulação Semiárido Agroecológico (ASA), Ecovida e a Reagro, compõem uma teia de redes que se espalham pelo país, aproximando atores locais, adotando estratégias de convivência com os territórios. As redes estão interligando atores, objetivando principalmente: a difusão dos conhecimentos agroecológicos por meio de caravanas, eventos de diversas ordens: formação/capacitação agroecológica, formação de associações e participação na construção das estratégias de comercialização da produção.

No sentido de perceber a intencionalidade na criação das redes, Finatto (2015) aponta que as Redes de Produção Orgânica têm como característica básica a verticalidade das relações e a orientação do mercado como elemento determinante na sua configuração. Nessas redes os agricultores são atores fundamentais, já que produzem a matériaprima, mas têm sua atuação limitada à esfera da produção. Segundo o autor, supracitado, as redes híbridas, também identificadas na pesquisa, revelam a complexidade dos processos envolvidos na produção do espaço agrário 
contemporâneo. Elas apresentam, em um mesmo conjunto de relações, princípios da produção agroecológica, orgânica e convencional.

Tecnologias Sociais (TS): Pouco mais de 6\% dos trabalhos "filtrados" observam o desenvolvimento de TS, normalmente a partir de estudos de caso. As TS constituem um conjunto de instrumentos, técnicas, metodologias transformadoras, desenvolvidas na interação entre pesquisadores e comunidades, visando solucionar questões-problema sociais locais.

O Projeto de Produção Agroecológica Integrada Sustentável - PAIS (NDIAYE, 2016), que tem como objetivo a produção diversificada agroecológica; tecnificar, gerar renda e alimentos para pequena(o)s produtora(e)s rurais, repercutiu nas publicações devido, também, à quantidade de projetos replicados pelo país financiados pelo Banco do Brasil.

Foi possível identificar projetos de TS em diferentes escalas. FERREIRA (2015), após uma análise de experiências do serviço de tecnologia alternativa - SERTA, avaliou que a qualificação técnico-profissional em agroecologia leva à gestão do desenvolvimento local sustentável. GRIGOLO (2016) aponta a importância da sustentabilidade da tecnologia social no manejo de sementes crioulas, como uma tecnologia da humanidade, sendo a(o)s agricultura(o)s guardiã(ões) desse saber.

MAZZEI (2018) destacou, por meio de processos de institucionalização dos programas governamentais articulados intersetorialmente, os projetos de economia solidária, associados ao desenvolvimento de TS, como facilitadores à (re)produção das práticas agroecológicas nos territórios.

Saúde: Perto de 6\% trazem as discussões para os valores da qualidade de vida e do bem estar humano. Nessa categoria a segurança alimentar e nutricional e o Direito Humano à Alimentação Adequada (DHAA) são destaques (CASTRO, 2016); questões ligadas à ética na alimentação (FILHO, 2016) e plantas medicinais (Política Nacional de Plantas Medicinais), dentre outros, também foram temas pesquisados. 
Outra discussão na categoria é a toxicologia. Estudos revelam questões graves envolvendo a saúde humana e impactos ambientais. Segundo SEGUESE (2016) há a correlação entre uso de agrotóxicos e o consumo de plantas transgênicas com doenças em humanos, no Paraná. Foi evidenciada a necessidade de aprofundamento nas investigações em relação à toxicologia dos alimentos produzidos pelo agronegócio.

A categoria saúde foi aquela identificada com menor percentual no balanço realizado, todavia, surge como crucial para a consolidação da agroecologia enquanto ciência e sua expansão enquanto prática e movimento. A conscientização crescente da sociedade, no que diz respeito à relação entre alimento-saúde-qualidade-de-vida, e as demandas sociais e mercadológicas por alimentos livres de agrotóxicos, pressionam os territórios à produção dentro de determinados padrões.

Outros: $12 \%$ dos trabalhos, por aproximação, trataram de outras temáticas, a saber: juventude, eficiência energética, história, ancestralidade e arte, que somam-se as partes constitutivas da dimensão política da Agroecologia brasileira. THERRIEN e NÓBREGATHERRIEN (2004) refletem que, na atualidade, com a complexidade galopante revelada pela sociedade da informação, o pesquisador é desafiado nas suas tentativas de desvendar o significado das múltiplas racionalidades e lógicas que nele convivem.

Segundo GOMES (2011: 34), abordando a epistemologia da dimensão política da Agroecologia, esta é uma ciência pós-normal, recomendada para se sair do reducionismo dominante, nas "comunidades restringidas de pares" levando a tomada de decisão para o âmbito das "comunidades estendidas de pares", por meio do debate mais amplo com toda a sociedade. Assim, promove-se a democratização e a circulação do conhecimento científico.

\section{Considerações finais}


Os conhecimentos científicos hierárquicos e dialógicos com o paradigma dominante influenciaram profundamente a relação sociedade-natureza ao longo dos séculos XVIII, XIX e XX, apresentando soluções parciais às demandas sociais. A agroecologia tem sua origem, enquanto saber científico, marcada pelos conhecimentos acadêmicos, principalmente da Agronomia e da Ecologia, incorporando outros saberes das comunidades tradicionais, tendo na aproximação de/com outras ciências como a Geografia e a ampliação da perspectiva interdisciplinar, que pode ser observada pela transversalidade encontrada nas temáticas desta pesquisa por meio dos parâmetros da busca.

Nesse sentido, um paradigma emergente requer um debate epistemológico (com alternativas), que se "alimenta" de pesquisas atuais, aqui representadas por teses e dissertações, bem como da realidade vivenciada pelos sujeitos e percebida pelos pesquisadores. A agroecologia desponta para o século XXI com hipóteses capazes de apresentar soluções mais sustentáveis para a questão alimentar e nutricional, observando a capacidade dos sistemas de absorverem impactos e desenvolverem as comunidades em suas dimensões.

A dimensão política da agroecologia, caracteriza-se por apresentar elevado grau de interdisciplinaridade, dialoga com suas práticas, seus movimentos e na (re)construção dos seus saberes. Ela é aderente à agricultura familiar dos povos tradicionais, apresentando-se como contraponto à agricultura convencional e aos grandes conglomerados agroindustriais. A inclinação dos governos em elaborar programas sob a temática da produção agroecológica passa pela pressão interna dos movimentos sociais, de acadêmicos, associações e grupos de consumidores, dentre outros.

De maneira geral, pôde-se perceber a agroecologia compreendida como instrumento político no reconhecimento de territorialidades a partir da racionalidade $\mathrm{da}$ sustentabilidade, numa perspectiva múltipla do ambiente na totalidade. As criações da Articulação Nacional da Agroecologia (ANA) e da Associação Brasileira de Agroecologia (ABA) foram fundamentais para os avanços da dimensão política da agroecologia e das suas pautas no Brasil. 
A agroecologia manifesta-se como ciência voltada à transversalidade do meio ambiente, mantendo os mais estreitos laços com paradigmas que remetem à interdisciplinaridade e à multidimensionalidade do conhecimento, em um cenário político-acadêmico que ainda precisa se abrir mais à questão sócio-ambiental.

Assim como outrora a Geografia conquistou a sua legitimidade frente ou em meio, por vezes, às demais ciências ou "disciplinas", a agroecologia vem buscando consolidar e ampliar o seu espaço. Após a aplicação da metodologia de levantamento e análise da bibliografia adotada para o presente texto, conclui-se que tanto a dimensão política é imprescindível para consolidação plena da agroecologia quanto o conhecimento das suas bases epistemológicas, a serem decodificadas constantemente sem a dicotomização dos saberes.

\section{Referências Bibliográficas}

ABRAMOVAY, Ricardo. Paradigmas do capitalismo agrário em questão. Anpocs: Estudos Sociedade e Agricultura, Rio de Janeiro, n.8, 1997.

AGUIAR, Janecleide. O Movimento dos Trabalhadores Rurais Sem Terra e o Projeto de Reforma Agrária Popular: as tecnologias digitais na construção das formas insurgentes de luta política no século XXI. 14/04/2016 459 f. Doutorado em Psicossociologia de comunidade ecologia social Instituição de Ensino: Universidade Federal do Rio de Janeiro, Rio de Janeiro, Biblioteca Depositária: CFCH.

ALTIERI, Miguel. Agroecologia: bases científicas para uma agricultura sustentável. Guaíba: editora agropecuária, 2002. 592 p.

ARAÚJO, Marlene. Educação ambiental nos colégios dos assentamentos organizados no MST: tendências conservadora e crítica. 29/04/2019 192 f. Doutorado em Educação Instituição de Ensino: Universidade Tuiuti do Paraná, Curitiba, Biblioteca Depositária: SLS.

BENSADON, Ligia. Tecendo projetos políticos: a trajetória da articulação nacional de agroecologia. 09/09/2016 undefined f. Mestrado em Ciências Sociais em Desenvolvimento, Agricultura e Sociedade Instituição de Ensino: Universidade Federal Rural do Rio de Janeiro, Seropédica, Biblioteca Depositária: undefined.

BRASIL. PNAPO - Política Nacional de Agroecologia e Produção Orgânica. Decreto Lei no 7.794, de 20 de agosto de 2020. 
Lei $n^{\circ} 11.326$, de 24 de julho de 2006: Estabelece as diretrizes para a formulação da Política Nacional da Agricultura Familiar e Empreendimentos Familiares Rurais. Diário Oficial da União. Brasília, DF.

. Instrução Normativa № 7, DE 17 de maio de 1999, revogada e substituída pela Lei no 10.831, de 23 de dezembro de 2003. Dispõe sobre a Agricultura Orgânica. Brasília: Congresso Nacional, 2003a. Disponível em<http://www.planalto.gov.br/ccivil_03/LEIS/2003/L10.831.htm\#art1>. Acesso em: 05 nov. 2020.

Decreto $\mathrm{n}^{\circ} 7.272$, de 25 de agosto de 2010. Regulamenta a Lei $\mathrm{n}^{\circ} 11.346$, de 15 de setembro de 2006, que cria o Sistema Nacional de Segurança Alimentar e Nutricional-SISAN, com vistas a assegurar o direito humano à alimentação adequada, institui a Política Nacional de Segurança Alimentar e Nutricional - PNSAN, estabelece os parâmetros para a elaboração do Plano Nacional de Segurança Alimentar e Nutricional, e dá outras providências. Brasília: Presidência da República, 2010.

CAPORAL, Francisco; COSTABEBER, José Antônio; PAULUS, Gervásio. Agroecologia: matriz disciplinar ou novo paradigma para o desenvolvimento rural sustentável. In.: CAPORAL, Francisco Roberto; AZEVEDO, Edisio Oliveira (Orgs.). Princípios $e$ perspectivas da agroecologia. Curitiba: Instituto Federal de Educação, Ciência e Tecnologia do Paraná - Educação a distância, 2011. pp. 45-82.

CASTRO, Franciléia. Construindo territórios livres de agrotóxicos para a promoção da agroecologia. 04/07/2016 128 f. Mestrado Profissional em Saúde Pública Instituição de Ensino: Fundação Oswaldo Cruz (FIOCRUZ), Rio de Janeiro, Biblioteca Depositária: Lincoln de Freitas Filho.

FACCO, Vinicius. Contribuição ao estudo da questão agrária brasileira: as contradições do Programa de Aquisição de Alimentos em assentamentos da reforma agrária.' 17/04/2019. 324 f. Doutorado em Geografia Instituição de Ensino: Universidade Federal do Paraná, Curitiba, Biblioteca Depositária: Biblioteca Ciência e Tecnologia.

FERREIRA, Germano. Qualificação técnico-profissional em Agroecologia: uma análise da experiência do serviço de tecnologia alternativa - SERTA. 25/09/2015 $113 \mathrm{f}$. Mestrado Profissional em Gestão do Desenvolvimento Local Sustentável Instituição de Ensino: Universidade de Pernambuco, Recife, Biblioteca Depositária: Lêucio Lemos, da Faculdade de Ciências da Administração de Pernambuco, FCAP/UPE.

FILHO, Eugênio. Agroecologia e saúde: estudo de caso em assentamento de reforma agrária no Nordeste brasileiro. 25/11/2016 108 f. Mestrado Profissional em Saúde 
Pública Instituição de Ensino: Fundação Oswaldo Cruz (FIOCRUZ), Rio de Janeiro Biblioteca Depositária: Lincoln de Freitas Filho.

FINATTO, Roberto. Redes de Agroecologia e produção orgânica na região Sul do Brasil: das intencionalidades à materialidade socioespacial. 06/05/2015 322 f. Doutorado em Geografia Instituição de Ensino: Universidade Federal de Santa Catarina, Florianópolis, Biblioteca Depositária: Biblioteca Central da UFSC.

GRIGOLO, Serinei. A renovação das estratégias de lutas na agricultura: o caso das festas das sementes crioulas no Sul do Brasil. 30/08/2016 294 f. Doutorado em Extensão Rural Instituição de Ensino: Universidade Federal de Santa Maria, Santa Maria, Biblioteca Depositária: Biblioteca Central da UFSM.

GRISA, Cátia e SCHNEIDER, Sérgio. Três Gerações de Políticas Públicas para a Agricultura Familiar e Formas de Interação entre Sociedade e Estado no Brasil. Revista de Sociologia Rural, Piracicaba-SP, Vol. 52, Supl. 1, p. 125-146, 2014.

GOMES, João Carlos. As bases epistemológicas da Agroecologia. In.: CAPORAL, Francisco Roberto; AZEVEDO, Edisio Oliveira (Orgs.). Princípios e perspectivas da agroecologia. Curitiba: Instituto Federal de Educação, Ciência e Tecnologia do Paraná - Educação a distância, 2011. pp. 13-44.

IHA, Mônica. A apropriação da agrofloresta na afirmação da reforma agrária: um estudo sobre o processo de recampesinização no assentamento Mário Lago em Ribeirão Preto - SP. 20/01/2017 308 f. Doutorado em Geografia (geografia humana) Instituição de Ensino: Universidade de São Paulo, São Paulo, Biblioteca Depositária: Biblioteca Florestan Fernandes - FFLCH.

LIMA, Filipe. As múltiplas faces do desenvolvimento rural: compreendendo as experiências de transição agroecológica nos municípios de Santa Cruz da baixa verde e de São Lourenço da Mata, PE. 08/01/2016 203 f. Doutorado em Extensão Rural Instituição de Ensino: Universidade Federal de Santa Maria, Santa Maria, Biblioteca Depositária: Biblioteca Central UFSM.

LOBO, Pitias. Educação popular: contradições, modismos e interesses. 30/08/2019 517 f. Doutorado em Educação Instituição de Ensino: UNIVERSIDADE FEDERAL DE GOIÁS, Goiânia, Biblioteca Depositária: Biblioteca Digital de Teses e Dissertações da Universidade Federal de Goiás.

LUZZI, Nilsa. O debate agroecológico no Brasil: uma construção a partir de diferentes atores sociais. 1/3/2007. 182f. Tese (Doutorado) - Programa de Pós-Graduação de Ciências Sociais em Desenvolvimento, Agricultura e Sociedade, Universidade Federal Rural do Rio de Janeiro, Biblioteca Depositária: Undefined. 
MARTINS, Adalberto. A produção ecológica de arroz nos assentamentos da região metropolitana de Porto Alegre: apropriação do espaço geográfico como território de resistência ativa e emancipação. 07/11/2017 296 f. Doutorado em Geografia Instituição de Ensino: Universidade Federal do Rio Grande do Sul, Porto Alegre Biblioteca Depositária: geo fragmentos.

MAZZEI, Bianca. O processo de implementação de programas federais de economia solidária de apoio a cooperativa de agroecologia. 07/02/2018 $161 \mathrm{f}$. Doutorado em Administração Pública e governo Instituição de Ensino: Fundação Getúlio Vargas (SP), São Paulo Biblioteca Depositária: Biblioteca Karl A Boedecker.

MENEZES, Leonardo. O Desenvolvimento da Agroecologia e as Instituições do Campo Científico Agrário. 26/04/2017 undefined f. Mestrado em Ciência Política Instituição de Ensino: Universidade Federal de São Carlos, São Carlos Biblioteca Depositária: Biblioteca Comunitária da UFSC.

MERCADO, Carmen. Reforma agraria e yvy marane'y: resistência campesina en la lucha por la tierra en el Paraguay. 28/03/2018 434 f. Doutorado em Geografia Instituição de Ensino: Universidade Federal do Paraná, Curitiba, Biblioteca Depositária: Biblioteca Central.

MELO, André. Pedagogia da alternância no Amazonas: uma práxis dos movimentos sociais da floresta. 17/01/2017 204 f. Doutorado em Sociedade e Cultura na Amazônia Instituição de Ensino: Universidade Federal do Amazonas, Manaus Biblioteca Depositária: Biblioteca da Universidade Federal do Amazonas.

MIRANDA, Rogério. (Contra)hegemonia e território do movimento dos trabalhadores rurais sem-terra (MST) no sudeste paraense. 20/09/2017 $380 \mathrm{f}$. Doutorado em Geografia (geografia humana) Instituição de Ensino: Universidade de São Paulo, São Paulo, Biblioteca Depositária: Biblioteca Florestan Fernandes - FFLCH.

MOLINA, Manuel. Introduccion a la agroecologia. Cuadernos técnicos. ed. SEAESociedad Espanhola de Agricultura Ecológica, 2011.

MONTEIRO, Denis. LONDRES, Flavia. Pra que a vida nos dê flor e frutos: notas sobre a trajetória do movimento agroecológico no BRASIL. IN: SAMBUICHI, Regina Helena Rosa. [et al.]. A política nacional de agroecologia e produção orgânica no Brasil: uma trajetória de luta pelo desenvolvimento rural sustentável - Brasília: Ipea, 2017.

MOURA, Maria da Conceição. Feminismo e Agroecologia: o sujeito político e a avaliação do ater- mulheres no rio grande do norte 2004-2016. 03/05/2018 271 f. Doutorado em Ciências Sociais Instituição de Ensino: Universidade Federal do Rio Grande do Norte, Natal, Biblioteca Depositária: BDTD-UFRN. 
MOURA, Iracema. Agroecologia na Agenda Governamental Brasileira: Trajetórias no Período 2003-2014. 29/04/2016 123 f. Doutorado em Ciência Tecnologia e Inovação em Agropecuária Instituição de Ensino: Universidade Federal Rural do Rio de Janeiro, Seropédica, Biblioteca Depositária: Biblioteca Central da UFRRJ.

MOSQUERA, Oscar. Virada ecológica e ecogovernamentalidade: uma analítica foucaultiana do sujeito ecológico na agroecopedagogia pernambucana' 09/03/2018 214 f. Doutorado em Educação Instituição de Ensino: Universidade Federal de Pernambuco, Recife, Biblioteca Depositária: Biblioteca Central.

NDIAYE, Aly. Análise do desenvolvimento do programa PAIS-Produção Agroecológica Integrada e Sustentável, enquanto estratégia para geração de renda e segurança alimentar e nutricional de sistemas de produção familiares: Estudo realizado nos estados do RJ e MS. 24/06/2016 50 f. Mestrado Profissional em Agricultura Orgânica Instituição de Ensino: Universidade Federal Rural do Rio de Janeiro, Seropédica, Biblioteca Depositária: Biblioteca Central da UFRRJ.

PEREZ-CASSARINO, Julian. A construção social de mecanismos alternativos de mercados no âmbito da Rede Ecovida de Agroecologia. 1/3/2012. 450 f. Tese (Doutorado) Programa de Pós-Graduação em Meio Ambiente e Desenvolvimento, Universidade Federal do Paraná, Curitiba, Biblioteca Depositária: undefined.

PORTO-GONÇALVES, Carlos Walter. A globalização da natureza e a natureza da globalização. 5 edição, Rio de Janeiro-RJ: Civilização brasileira, 2013.

RODRIGUES, Hélio. A Agroecologia no Território Norte do Espírito Santo: uma análise à luz do desenvolvimento territorial sustentável. 04/04/2017 224 f. Mestrado em Sociologia e Ciência Política Instituição de Ensino: Universidade Federal de Santa Catarina, Florianópolis Biblioteca Depositária: BU UFSC.

ROSA, Vanessa. De MARX a ALTIERI: limites do balizamento jurídico para a produção agroecológica nos marcos do capitalismo. 05/08/2019 250 f. Doutorado em Direito Político e Econômico Instituição de Ensino: Universidade Presbiteriana Mackenzie, São Paulo Biblioteca, Depositária: Biblioteca George Alexander - Setorial Direito.

SANTOS, Milton, SILVEIRA, Maria Laura. O Brasil: território e sociedade no início do século XXI. 7 edição, Rio de Janeiro-RJ, Record, 2005.

SEGHESE, Marcos. Agrotóxicos, transgênicos na agricultura e saúde humana no estado do Paraná - Brasil. 29/07/2016 75 f. Mestrado Profissional em Agroecologia Instituição de Ensino: Universidade Estadual de Maringá, Maringá, Biblioteca Depositária: Biblioteca da Universidade Estadual de Maringá. 
SEVILLA-GUZMÁN, Eduardo. La agroecologia como estrategia metodológica de transformación social. [s.l.]: [s.n.], 2006. Disponível em: http://www.cristinaenea.eus/eu/download/microsites/ficheros/Agroecologia y tra nsformacion social.pdf Acessado em 15/04/2021.

SILVA, Marco Antônio. Questão Agrária e Luta pela Terra: a consolidação dos assentamentos de Reforma Agrária do MST no Distrito Federal e Entorno. 31/03/2017 264 f. Doutorado em Política Social Instituição de Ensino: Universidade de Brasília, Brasília, Biblioteca Depositária: Biblioteca Central - UnB.

THERRIEN, Jaques, NÓBREGA-THERRIEN, Sílvia. Trabalhos científicos e o estado da questão: reflexões teórico-metodológicas. EAE [Internet]. 2004. Disponível em: http://publicacoes.fcc.org.br/index.php/eae/article/view/2148/2105 Acessado em 16/04/2021.

VIEIRA, Leonice. A pedagogia da alternância do curso em agroecologia: um estudo de caso no IFSul. 21/02/2017 197 f. Mestrado Profissional em Educação e Tecnologia Instituição de Ensino: Instituto Federal de Educação Ciência e Tecnologia Sul-riograndense, Pelotas, Biblioteca Depositária: Instituto Federal de Educação, Ciência e Tecnologia Sul-rio-grandense / Campus Pelotas.

ZANELLI, Fabricio. Educação do Campo e Territorialização de Saberes: Contribuições dos intercâmbios agroecológicos. 25/03/2015 146 f. Mestrado em Educação Instituição de Ensino: Universidade Federal de Viçosa, Viçosa, Biblioteca Depositária: Biblioteca Central da Universidade Federal de Viçosa.

ZARZAR, Andrea. Movimentos sociais de mulheres rurais no Brasil: a construção do sujeito feminista. 12/04/2017 300 f. Doutorado em Sociologia Instituição de Ensino: Universidade Federal de Pernambuco, Recife, Biblioteca Depositária: Biblioteca Central da UFPE.

Data de Submissão: $20 / 12 / 2020$

Data do Aceite: 07/04/2021 